\title{
QUARTO DE DESPEJO: BREVE REFLEXÃO A PARTIR DOS CONCEITOS DE SUJEITO E AGÊNCIA DE JUDITH BUTLER
}

\section{ROOM OF GARBAGE: BRIEF REFLECTION FROM JUDITH BUTLER SUBJECT CONCEPTS AND AGENCY}

Elna Dias Cardoso

\begin{abstract}
RESUMO: A finalidade deste artigo é analisar a narrativa de Carolina Maria de Jesus descrita em Quarto de despejo: diário de uma favelada (2005), a partir dos conceitos de sujeito e agência no pensamento de Judith Butler. Trata-se de análise documental orientada pelos seguintes questionamentos: a) como a história de vida de Carolina de Jesus é apresentada no livro? b) quais os instrumentos de resistência utilizados por Carolina de Jesus para enfrentar a realidade de exclusão que lhe era imposta? A análise foi fundamentada nos seguintes livros: Al lado de uno mismo: em lós limites de La autonomia sexual; Vida precária; Cambio Del sujeto: La política dela resignificación radical de Judith Butler.; Máscaras del deseo: uma lectua del deseo em Judith Butler.; e La vida psíquica del poder. $\mathrm{O}$ trabalho aponta para o processo de resistência e de agência construído por Carolina de Jesus, evidenciando uma escrita de empoderamento em um contexto marcado pela desigualdade social.
\end{abstract}

Palavras-chave: Agência. Narrativa. Quarto de despejo. Sujeito.

ABSTRACT: The purpose of this article is to analyze the narrative of Carolina Maria de Jesus described in Room of Garbage: diary of a favelada (2005), from the concepts of subject and agency in the thought of Judith Butler. It is a documentary analysis guided by the following questions: a) How is the life history of Carolina de Jesus presented in the book? b) What were the instruments of resistance used by Carolina de Jesus to face the reality of exclusion that was imposed on her? The analysis is based on the following books: On the side of one self: on the border of sexual autonomy; Precarious life; Subject Change: The Politics of Judith Butler's radical resignification; Masks of Desire: a lectua del deseo in Judith Butler; e The psychic life of power. The work points to the process of resistance and agency built by Carolina de Jesus, evidencing a writing of empowerment in the context marked by social inequality.

Keywords: Agency. Narrative. Room of garbage. Subject.

\section{INTRODUÇÃ̃O}

Quarto de despejo trata-se do diário de Carolina Maria de Jesus, uma mulher negra, da cidade de Sacramento (MG), que estudou até o segundo ano do ensino fundamental, moradora da extinta favela Maloca, do Canindé, zona norte de São Paulo.

Educação, Psicologia e Interfaces, v. 2, n. 1, p. 152-166, Janeiro/Abril, 2018 
Quarto de despejo: breve reflexão a partir dos conceitos de sujeito e agência de Judith Butler

A partir da década de 1940, temos um crescimento de migrantes de todos os estados, especialmente nordestinos, em direção a São Paulo, procurando trabalho e melhores condições de vida. Carolina seria uma dessas migrantes que saiu de espaços interioranos ${ }^{1}$ para a capital paulista. Essa entrada de pessoas em São Paulo conduziu a uma urbanização desordenada, muitos migrantes sem moradia, assim como Carolina, ocuparam terras desocupadas e devolutas próximas aos morros (SILVA, SANTOS, s/d). Esses espaços não possuíam nenhuma infra-estrutura, e as pessoas viviam em péssimas condições, muitas encontraram no lixo a fonte de sobrevivência, dentre elas, a escritora do livro Quarto de despejo.

O diário apresenta o cotidiano da favela, as concepções de Carolina sobre as questões econômicas, políticas e sociais, sentimentos, entre outras reflexões que emergem das vivências da escritora. As narrativas foram escritas em cadernos que encontrava no lixo.

Os registros começaram no dia 15 de julho de 1955, dia do aniversário de sua filha Vera Eunice. Entretanto, ganhou notoriedade em 1960, quando o jornalista Audálio Dantas, depois de publicar no artigo Folha da Noite (1958), revista O Cruzeiro (1959), empenha-se na publicação dos relatos.

A apresentação do livro é escrita pelo jornalista. Nos parágrafos iniciais do livro, temos uma descrição do lugar que vive Carolina. Audálio Dantas parece ensejar uma escrita particularizada do ambiente, buscando levar o leitor a adentrar no barraco $\mathrm{n}^{\circ} 9$.

\begin{abstract}
O barraco é assim: feito de tábuas, coberto de lata, papelão e tábuas também. Tem dois cômodos, não muito cômodos. Um é sala-quartocozinha, nove metros quadrados, se muito for; e um quarto quartinho, bem menor, com um lugar para uma cama justinha lá dentro. A humanidade dele é esta: Carolina, Vera Eunice, José Carlos, João José, e 35 cadernos. Tem mais coisas dentro dele, que a luz da janelinha deixa a gente ver: um barbante esticado, quase arrebentando de trapos pendurados, mesinha quadrada, tabua de pinho; e fogareiro de lata e lata-de-botar-água e lata-de-fazer café e lata-de-cozinhar; tem também guarda-comida escuro de fumaça e cheio de livros velhos; e mais duas camas, uma sala-quarto-cozinha e outra no quarto assim chamado (DANTAS apud JESUS, 1960, s/p).
\end{abstract}

A exposição do contexto, realizada pelo jornalista Audálio Dantas, já sinaliza a intenção de fazer o leitor "olhar pelas lentes" dele. O trecho: "A humanidade dele é esta: Carolina, Vera Eunice, José Carlos, João José, e 35 cadernos", demonstra o que o

Educação, Psicologia e Interfaces, v. 2, n. 1, p. 152-166, Janeiro/Abril, 2018. DOI: https://doi.org/10.37444/issn-2594-5343.v2i1.119 
jornalista identifica como humanitário em um ambiente marcado pela pobreza. Entre os elementos citados por Adáulio temos os cadernos, diários de Carolina, como um instrumento que ganha vida por apresentar um registro de vivências.

Expressões como "irmã nossa", "vizinha nossa, ali da favela do Canindé" (s/p), evidenciam o intuito do jornalista de aproximar a experiência de Carolina dos leitores. Assim, organiza um contexto que busca demonstrar que as pessoas que vivem ali (neste caso, representada por Carolina), mesmo em condições de vida distintas das nossas, são pessoas como nós, com sonhos e expectativas. Ou seja, são pessoas comuns ${ }^{2}$.

$\mathrm{Na}$ apresentação do jornalista também aparece o seu lugar de fala: integrante da classe média. E assim, diferencia a apreensão de quem vive essa realidade daqueles que não pertencem a esse universo.

No fim da rua, a gente já viu algumas dezenas de infelicidades e tem vontade de fechar os olhos e tampar os ouvidos [...] Dá para ver, assim numa hora, mais de 150 barracos, abrigando a miséria mais miserável do mundo. Uma miséria tão grande que a gente nem entende ela. $\mathrm{Ou}$ não quer entender verdade verdadeira. Se a gente entendesse, a favela não estava plantada lá na beira do Tietê. Já que está, o melhor é a gente fechar os olhos e tampar os ouvidos. Convém.

São eles que entendem - os que moram lá e degradam lá, na fome, na lama, no lixo, na cama. Tem menino barrigudo que entende mais do que a gente (DANTAS apud JESUS, 1960, s/p).

Neste cenário assinalado pela pobreza, o jornalista apresenta Carolina Maria de Jesus, como uma mulher que encontrou na favela o caminho para sobrevivência. "Sua vida, nestes anos todos de favela, tem sido uma luta heróica de sobrevivência: sair de manhã, procurar papeis no lixo, arranjar dinheiro para almoçar, sair de tarde, no mesmo caminhar, arranjar dinheiro para o jantar. O resto é fome" (s/d). Para a publicação do diário, o jornalista optou pelos seguintes procedimentos metodológicos:

Selecionei trechos, sem alterar uma palavra, para compor o livro [...] a repetição seria inútil. Daí a necessidade de cortar, selecionar as histórias mais interessantes. [...]

[...] tenho de acrescentar que, alguns poucos trechos, botei uma ou outra vírgula, para evitar interpretação dúbia de frases. Algumas cedilhas desapareceram, por desnecessárias, e o verbo haver, que Carolina entende apenas com um a assim soltinho, confundido facilmente com o artigo, ganhou um $\mathbf{h}$ de presente.

De meu, no livro, há ainda uns pontinhos que aparecem assim (...) e indicam supressão de frases. Quando os pontinhos estão sozinhos, sem

Educação, Psicologia e Interfaces, v. 2, n. 1, p. 152-166, Janeiro/Abril, 2018 
( ) nos parágrafos, querem dizer que foi suprimido um trecho ou mais de um trecho da narrativa original. Há também de dizer que há muitos dias sem registro, ou porque Carolina deixou de escrever ou que foram suprimidos na passagem para o livro. De julho de 1955 a maio de 1958, ela deixou de escrever o diário. Não sei qual a razão. Desesperança, talvez (DANTAS apud JESUS, 1960, s/p).

A organização metodológica merece alguns comentários: 1) toda construção é parcial. No livro em questão, a nomeação dos trechos foi realizada pelo jornalista, ou seja, ele também é um construtor da narrativa apresentada; 2) o diário, segundo Demétrio (apud CAZAROTTO, 2006), é expressão de singularidade por ser emocional, relacional e significativa. Emocional, porque a narração da própria vida implica num sentir o que se viveu, o que está se vivendo e o que se almeja viver. Relacional, porque a história passa a ser percebida como uma história compartilhada, construída com o outro. E significativa, porque provoca um processo de reflexão. Nesse sentido, o diário não é uma narrativa sem artifício, uma vez que ele é uma importante versão de uma intersubjetividade; 3 ) Ao expor à história de Carolina e também de outros sujeitos que convivam com ela, podemos dizer que o diário apresenta-se como um inventivo texto polifônico. Pois, como afirma Dantas (1960, s/p) o diário "transformou-se em voz de protesto. E há muitos anos grita, bem alto, em seus cadernos, grito de todos os dias. Os seus gritos e os gritos dos outros, em diário".

O livro é apresentado como um "grito de protesto" com a expectativa de que "os de cá de fora olhem para dentro e vejam melhor o Quarto de Despejo" (DANTAS 1960, s/p). Assim sendo, a porta do Quarto de Despejo é aberta para o mundo.

\section{MÉTODO}

Neste trabalho empregamos a análise documental que se caracteriza pela pesquisa “[...] de materiais que não receberam ainda um tratamento analítico, ou que ainda podem ser reelaborados de acordo com os objetos da pesquisa" (GIL, 2008, p. 45). O uso de documentos na pesquisa propicia uma riqueza de informações nos diferentes campos do conhecimento, aproximando a compreensão do universo pesquisado na sua contextualização histórica e social (SÁ-SILVA; ALMEIDA; GUINDANI, 2009).

Neste contexto, o ponto de partida de um estudo científico não consiste na análise de um documento, mas na elaboração de perguntas que devem ser realizadas. Segundo Eliana Marta Teixeira Lopes e Ana Maria de Oliveira Galvão (2001, p.79) “[...] o que

Educação, Psicologia e Interfaces, v. 2, n. 1, p. 152-166, Janeiro/Abril, 2018.

DOI: https://doi.org/10.37444/issn-2594-5343.v2i1.119 
determina o que são as fontes é exatamente o [...] problema problematizado." Nessa direção, os questionamentos que o pesquisador formula ao documento são tão importantes quanto o próprio documento.

Partindo dessas concepções, alguns questionamentos foram elaborados para analisar o livro Quarto de Despejo: a) como a história de vida de Carolina de Jesus é apresentada no livro? b) quais os instrumentos de resistência utilizados por Carolina de Jesus para enfrentar a realidade de exclusão que lhe era imposta? Para análise, utilizamos os conceitos de sujeito e agência no pensamento de Judith Butler, examinando os seguintes livros: Al lado de uno mismo: em lós limites de La autonomia sexual; Vida precária; Cambio Del sujeto: La política dela resignificación radical de Judith Butler; Máscaras del deseo: uma lectua del deseo em Judith Butler; e La vida psíquica del poder.

\section{RESULTADOS E DISCUSSÃO}

Neste momento irei discorrer de forma sucinta sobre o pensamento de Judith Butler e, a partir desta reflexão pensar a primeira parte do diário de Carolina. Judith Butler é uma filosofa norte-americana, pós-estruturalista. Recebeu a influência de teóricos feministas, como Simone de Beauvoir, Luce Irigaray e Adriane Rich, e também do denominado "giro linguístico", como John Austin, Michel Foucault, Jacques Derrida e Gilles Deleuze. Seu pensamento problematiza os binarismos, discutindo as dicotomias gênero/cultura x sexo/biológico.

Na concepção da autora, sexo e gênero são intercambiáveis, pois ambos são derivados de constructos sociais (BUTLER, 2006). Nessa perspectiva, assevera que Beauvoir possui uma concepção biologicista do gênero, que não a deixa pensar em outras possibilidades, além de homem e mulher (FEMENÍAS, 2000). Butler concebe gênero como performance, propõe repensar o corpo não como um elemento natural, mas como uma "superfície politicamente regulada".

Segue a linha foucaultiana de que o discurso é constitutivo, produtivo e performativo de subjetividades, uma vez que o corpo em um determinado momento histórico é nomeado de sexuado, legitimando assim, práticas sociais de controle, e domesticando o desejo. Entretanto, para a autora:

o desejo é algo que nos faz mover e que tem a possibilidade de criar e modificar seus objetos de desejo, podemos ressignificar a linguagem

Educação, Psicologia e Interfaces, v. 2, n. 1, p. 152-166, Janeiro/Abril, 2018 
Quarto de despejo: breve reflexão a partir dos conceitos de sujeito e agência de Judith Butler

rompendo sempre com os significados pré-fixados dos sexos e gêneros, entre outras categorias (GALLINA, 2008, p.2).

Butler compreende o sujeito como algo que é construído discursivamente. Nessa perspectiva,

nenhum indivíduo torna-se sujeito sem antes ter sido sujeitado ou passado por um processo de subjetivação. Tanto em Foucault como em Butler, o sujeito encontra suas próprias possibilidades de resistência ou de subversão aos mandatos socais que o limitam (FURLIN, 2003, p. 396).

Essa possibilidade acontece por atos de liberdade, definida pela autora como agência, no qual o desejo constitui um elemento fundamental. Nesse entendimento, o desejo é pré-linguístico, metafísico, e antecedente à construção da linguagem que o subscreve.

\subsection{Narrativas de Carolina}

Neste momento, analisarei os registros da escritora. Para realizar essa tarefa apresento os trechos do diário como atos de uma peça teatral, buscando caracterizar três atos da vida social e, assim problematizar as questões que emergem desse discurso. Essa opção metodológica revela o lugar que me posiciono na produção do conhecimento, como estudante de sociologia, assim como as situações que procuro discutir.

\section{Ato 1: Iniciando o registro}

Carolina inicia seus relatos no diário no dia 15 de julho de 1955 , marcando seu lugar de fala: mulher, mãe solteira, chefe de família, trabalhadora (diarista e catadora de lixo), favelada.

Aniversário de minha filha Vera Eunice. Eu pretendia comprar um par de sapatos para ela. Mas o custo dos gêneros alimentícios nos impede a realização dos nossos desejos. Atualmente somos escravos do custo de vida. Eu achei um par de sapatos no lixo, lavei e remendei para ela calçar.

Eu não tinha um tostão para comprar pão.

Passei o dia indisposta. Percebi que estava resfriada. A noite o peito doía-me, comecei tussir. Resolvi não sair a noite para catar papel. Procurei meu filho João José. Ele estava na rua Felisberto de Carvalho, perto do mercadinho. O ônibus atirou um garoto na calçada e a turba afluiu-se. Êle estava no nucleo. Dei-lhe uns tapas e em cinco minutos êle chegou em casa (JESUS,1960, p.13)

Educação, Psicologia e Interfaces, v. 2, n. 1, p. 152-166, Janeiro/Abril, 2018.

DOI: https://doi.org/10.37444//issn-2594-5343.v2i1.119 
As palavras utilizadas e a disposição do texto trechos evidenciam a compreensão da autora sobre o contexto socioeconômico, e como os diferentes sujeitos estão atrelados a um sistema que os oprime. Carolina também demonstra as estratégias criadas diante dos recursos que possui, ao dizer que lavou e costurou os sapatos para a filha. É possível perceber também que a narrativa é conduzida por uma mulher que se coloca como narradora da própria história delineando formas de enfrentar de restrições normativas e políticos-econômicas.

\section{Ato 2: Carolina de Jesus e as dinâmicas de poder}

Carolina lembra que recebeu uma educação voltada às "atividades de mulher": "Eu nada tenho que dizer da minha saudosa mãe. Ela era muito boa. Queria que eu estudasse para professora. Foi a contingência da vida que lhe impossibilitou concretizar o seu sonho" (JESUS, 1960, p. 43). A autora recebeu uma educação que, as normas demarcavam o "lugar da mulher", não apenas dentro do âmbito doméstico, mas também no espaço público, uma vez que o desejo de sua mãe era que ela fosse professora, uma das profissões desejáveis para a mulher na época. Entretanto, essas possibilidades de estudo, e consequentemente de ingresso no campo profissional variavam conforme a classe social. Assim, garotas de estratos sociais pobres, iniciavam cedo suas atividades produtivas, seja dentro de casa, ou fora como operárias, garçonetes etc.(PRIORE, 2004). Carolina é um exemplo disso, pois aos 10 anos, assim como muitas meninas negras, já trabalhava como lavradora.

Observa-se, o que Butler (1999), denomina de um processo de submissão primária ao poder no qual o sujeito passa a internalizar as normas e valores desde a infância. Temos a mediação entre os condicionamentos sociais exteriores e a subjetividades dos sujeitos, que se apresentam nas concepções, apropriações e ações experenciadas ${ }^{3}$.

Nesse transcurso de assimilação dos princípios sociais ocorridos na psique, temos também a elaboração da distinção entre a vida interior e exterior. Consciência, que segundo Furlin (2013) suscita as condições de resistência e de reflexividade, permitindo ao sujeito contestar o poder normalizador que restringe e gere os desejos de sua própria possibilidade, no campo das experiências.

Educação, Psicologia e Interfaces, v. 2, n. 1, p. 152-166, Janeiro/Abril, 2018 
Quarto de despejo: breve reflexão a partir dos conceitos de sujeito e agência de Judith Butler

As condições de vida de Carolina, assinaladas pela pobreza, assim como os construtos socioculturais da conduta feminina no período de 1950, são componentes para o surgimento do desejo de Carolina de modificar a sua vida.

No primeiro momento, esse desejo emerge no limite imposto as relações amorosas que as mulheres deveriam ter. As vivências da escritora contrariaram as representações da figura feminina destinada ao casamento e a maternidade. Carolina apresenta novos posicionamentos a não concordar com o matrimônio.

Elas aludem que não sou casada. Mas eu sou mais feliz do que elas. Elas têm marido. Mas, são obrigadas a pedir esmolas. São sustentadas por associações de caridade. [...] E elas, tem que mendigar e ainda apanhar. Parece tambor. A noite enquanto elas pedem socorro eu tranquilamente no meu barraco ouço valsas vienenses. Enquanto os esposos quebram as tabuas do barracão eu e meus filhos dormimos socegados. Não invejo as mulheres casadas da favela que levam vida de escravas indianas.

Não casei e não estou descontente (JESUS, 1960, pp. 17-18).

No diário a escritora sinaliza as relações que estabeleceu, assim como, as percepções que acreditava que a comunidade possuía a seu respeito.

Ablui as crianças, aleitei-me e ablui-me e aleite-me. Esperei até as 11 horas, certo alguém. Ele não veio (JESUS, 1960, p. 13).

Diz que sou preferida pelos homens bonitos e distintos. E ganho mais dinheiro do que ela (JESUS, 1960, pp.16-17).

Aqui, todas impricam comigo. Dizem que falo muito bem. Que sei atrair os homens (JESUS, 1960, p.24).

O posicionamento da autora desafiava a ideia do destino natural feminino e da inexorável atribuição dos construtos socioculturais para homens e mulheres na década de 1950. Pois, ser mãe solteira nesse período era um comportamento desviante, e as mulheres sofriam as consequências desse ato com a propagação do estigma social, da discriminação e do abandono. Ações desse tipo representavam uma contestação dos arquétipos femininos. Carolina demonstrava alegria por viver de forma independente e não sofrer agressões físicas, sublinhando que nenhum homem suportaria viver com uma mulher que acorda e dorme com um lápis na mão.

O desejo de viver de forma distinta da maioria das mulheres da época ativa a transgressão de uma ordem que era imposta pelas normas sociais. Assim, como Antígona, na literatura clássica, luta para que sua voz de mulher seja ouvida, buscando anular um

Educação, Psicologia e Interfaces, v. 2, n. 1, p. 152-166, Janeiro/Abril, 2018.

DOI: https://doi.org/10.37444//issn-2594-5343.v2i1.119 
decreto de Creonte $^{4}$, Carolina também reage aos imperativos da sociedade de um lugar não legitimado para viver relações afetivas restritas ao universo masculino, e também ocupar posições comumente designadas aos homens, como ser chefe de família.

$\mathrm{Na}$ análise que Butler (2009) faz da ação de Antígona de contestar o decreto de

Creonte, assinala que o seu desejo se vincula a uma prática transformadora que abre as portas para uma mudança política. O desejo, portanto, gera a possibilidade de mudança. Acreditamos que no caso de Carolina também podemos seguir essa linha de pensamento. No diário da escritora temos a exposição de como esse movimento acontece, inclusive os sentimentos que emergem nesse processo de construção do desejo. Pois, acreditamos que ação de mudança não acontece sem embates internos, que apresentam os ditames sociais internalizados.

A transmutação de posições consideradas masculinas, como por exemplo, ser chefe de família, em alguns momentos provocavam sentimentos de incertezas e revoltas. Como no dia em que Carolina não tinha dinheiro para comprar comida, a filha Vera Eunice estava doente e João Carlos rejeitava ir à escola, porque não tinha sapatos e estava frio. A escritora foi catar papel extremamente nervosa:

Eu estava tão nervosa! Acho que se eu estivesse nunm campo de batalha, não ia sobrar ninguém com vida. Eu pensava nas roupas pra lavar. Na Vera. E se a doença fosse piorar? Eu não posso contar com o pai dela. Ele não conhece a Vera. E nem a Vera conhece ele. Tudo na minha vida é fantástico. Pai não conhecer filho, filho não conhece pai (JESUS, 1960, p.28).

No entanto, quando Carolina não consegue alimento do dia, ainda reproduz em palavras os esquemas de pensamento dominantes internalizados ao longo de sua vida. Quando afirma: "Preciso ser tolerante com meus filhos. Eles não têm ninguém no mundo a não ser eu. Como é pungente a condição de mulher sozinha sem um homem no lar" (p. 24). Ou ainda, quando revela o encontro com Mariana, outra moradora da favela: "Uma mulher agradável e decente. Tem 9 filhos e um lar modelo. Ela e o esposo tratam-se com iducação. Visam apenas viver em paz" (JESUS, 1960, p. 23).

Vemos deste modo, que a construção de uma nova subjetividade passa por um processo, no qual o desejo se sobrepõe aos preceitos instituídos socialmente, gerando uma possibilidade de resistência. Esse é um ato político que se faz presente no espaço público. No jogo das relações de poder, Carolina, assim como Antígona, produz para a esfera

Educação, Psicologia e Interfaces, v. 2, n. 1, p. 152-166, Janeiro/Abril, 2018 
pública uma mulher que não era revelada, ou seja, uma mulher independente, livre das amarras patriarcais, que reafirmava outra forma de viver. As ideias sobre o comportamento feminino apresentado nos relatos ecoaram entre algumas leitoras como um dos símbolos da causa feminina no país (TOLEDO, 2011). Nessa direção, ainda comparando a escritora com Antígona podemos afirmar que:

Mesmo sem estar liberta das formas tradicionais do poder, ela produz uma nova base para legitimar o seu discurso, quando coloca em ação o seu desejo. Isso mostra que [...] qualquer insurreição política se baseia nas normas existentes para produzir algo novo. Isto é, não se trata de uma libertação, e sim de uma "subversão crítica", uma ressignificação radical (FURLIN, 2013, p. 398).

O que a escritora do Quarto de despejo faz é uma apropriação da autoridade de um poder que se reverte em possibilidade de agência, demonstrando assim, a ambivalência do sujeito ser constituído pelo poder e usá-lo de modo "transgressor", transformador dos paradigmas vigentes (FEMENÍAS, 2000).

O poder da agência se configura como resistência política, assim Butler (2010, p.9) assevera: “A agência excede ao poder que lhe faz possível”.

Sempre que houver um contexto normativo que limita o desejo de ação de um sujeito, o próprio limite ativa a consciência e gera resistência ao poder tronando-se potência, ou seja, produz novas possibilidades que excedem ao poder normativo, ressignificando práticas e comportamentos culturais. É, então, nesses focos de resistência/agência que ocorrem os processos de transformação sociocultural (FURLIN, 2013, p. 401).

Vemos, portanto que, o motor da agência é o desejo, que se manifesta como propulsor de mudança, ao acionar a consciência reflexiva acerca das balizes que o poder estabelece ao sujeito. No livro aqui analisado, podemos dizer que a escritora inicia um processo de resistência, que ganha certa representatividade diante de outras mulheres da comunidade. Assim sendo, ainda que essas mulheres não aprovassem as concepções de Carolina, elas pareciam visualizar na escritora um sujeito que poderia ordenar a favela.

Esse fato surge, quando as mulheres pedem a diarista para repreender o ato de um morador: "Quando eu inha chegando no portão encontrei uma multidão. Crianças e mulheres, que vinham reclamar que o José Carlos havia apedrejado suas casas. Para eu repreendê-lo" (JESUS, 1960, p. 15). 
No registro do diário de 1955, não temos a questão da etnia problematizada como um elemento importante na constituição da identidade de Carolina. Aparecem situações que ela descreve como discriminatórias: "Quando eu passava perto do campo do São Paulo, várias pessoas saiam do campo. Todas brancas, só um preto. E o preto começou insultar-me: - Vai catar papel, minha tia? Olha o buraco, minha tia" (JESUS, 1960, p. 15). Entretanto, essas situações não assumem relevância em sua narrativa. Em Diário de Bitita $^{4}$ é que Carolina apresenta suas inquietações sobre a questão. O que nos conduz a outro movimento do processo de resistência da autora. Pois, como afirma bell hooks (1995), tecer diálogos com as categorias raça, classe e gênero é uma forma de mulheres negras refletirem sobre suas experiências e ressignificarem/transformarem suas realidades.

\section{Ato 3: O cotidiano da favela: o livro como denúncia}

Desde a primeira descrição no diário, Carolina narrou às misérias e lamentações em relação à condição de vida. No livro, a escritora relata não apenas o seu cotidiano, mas também "as lambanças dos favelados", descrevendo o assistencialismo das instituições na doação de alimentos, a violência doméstica, aspectos morais e a religiosidade.

$\mathrm{Eu}$ estava indisposta, resolvi benzer-me. Abri a boca duas vezes, certifiquei-me que estava com mau olhado (JESUS, 1960, p. 13).

No rio chegou Adair Mathias, lamentando que sua mãe era forte, mas que agora lhe puzeram feitiço. Que o curador disse que era feiticeira (JESUS, 1960, p. 27).

Tem as igrejas que dá pão. Tem o São Francisco que todos os meses dá mantimentos, café, sabão etc. (JESUS, 1960, p. 20)

Hontem eu bebi uma cerveja. Hoje estou com vontade de beber outra vez. Mas, não vou beber. Não quero viciar. Tenho responsabilidade. Os meus filhos! E o dinheiro gasto com cerveja faz falta par o escencial. $\mathrm{O}$ que eu reprovo nas favelas são os pais que mandam os filhos comprar pinga e dá as crianças para beber (JESUS, 1960, p. 22).

As relações de vizinhança são marcadas por movimentos de proximidade e conflitos. Assim, Carolina escreve situações em que pede emprestados mantimentos a vizinha e, em outros narra situações de confusões porque algumas vizinhas não gostam de seus filhos. Para a autora, não havia nada de benéfico na favela, como podemos observar nesse trecho: "O único perfume que exala na favela é a lama podre, os excrementos e a pinga" (JESUS, 1960, p.48).

Educação, Psicologia e Interfaces, v. 2, n. 1, p. 152-166, Janeiro/Abril, 2018 
Quarto de despejo: breve reflexão a partir dos conceitos de sujeito e agência de Judith Butler

Por não gostar de viver nesse espaço populacional, a favelada ampara-se na escrita, e, por assim fazer, via-se diferente das pessoas que lá viviam; ao mesmo tempo, era vista com animosidade pelos moradores do Canindé. As motivações para o registro de Carolina lembram a razões exposta por Anzaldúa (2000, p. 232), ao escrever uma carta para as mulheres negras do terceiro mundo:

a escrita me salva da complacência que me amedronta [...] Porque o mundo que crio na escrita compensa o que o mundo real não me dá. No escrever coloco ordem no mundo, coloco nele uma alça para poder segurá-lo [ ] Escrevo para registrar o que os outros apagam quando falo, para reescrever as histórias mal escritas sobre mim, sobre você.

A publicização das situações da favela sempre anunciada pela escritora não recebia aprovação dos outros moradores:

Vou escrever um livro referente a favela. Hei de citar tudo aqui se passa. E tudos que vocês me fazem.

A Silvia pediu-me para retirar o seu nome do meu livro. Ela disse: Você é mesmo uma vagabunda (JESUS, 1960, p. 21).

Ao seu modo, Carolina apresentou uma escrita de protesto, expondo seu olhar empírico, pois conforme Bakhtin (1992), o discurso não é neutro, sendo carregado de intenções a cada sentença elaborada. No livro temos a presença de múltiplas vozes: a da pobreza, da emancipação feminina, questões pessoais etc. Vozes que retratam o universo de sujeitos invisibilizados. O diário foi o único instrumento encontrado pela diarista para expor as suas vivências e a realidade de exclusão que se encontrava aquelas pessoas.

Perrot (1991, p. 97), ao analisar o processo de escrita das mulheres em seus cadernos pessoais, ressalta que durante muito tempo, a autorização que recebiam para a escrita era o direito de anotar na sala, junto dos homens da casa.

Uma mulher na intimidade de seu quarto, pode escrever um livro ou um artigo de jornal que a introduzirão no espaço público. É por isso que a escritura suscetível de uma prática domiciliar (assim como a pintura), é uma das primeiras conquistas femininas, e também uma das que provocaram mais forte resistência.

Com a opressão feminina, o diário foi a única via de produção literária possível para as mulheres. O diário é: "um texto sem destinatário, o diário íntimo aparece na confluência dos séculos XVIII e XIX, coincidindo com a agitação política, a profusão

Educação, Psicologia e Interfaces, v. 2, n. 1, p. 152-166, Janeiro/Abril, 2018.

DOI: https://doi.org/10.37444/issn-2594-5343.v2i1.119 
literária e o aumento da alfabetização, principalmente feminina, semi-oficial" (PERROT, 1991, p. 99).

O diário é, portanto, o artefato que Carolina utiliza para ressignificar suas experiências $^{5}$ e provocar mudanças, uma vez que com a publicação do Quarto de despejo, temos uma obra que, apresenta uma forte e singular representação da dinâmica social urbana, a partir do olhar daqueles que são lançados à margem da sociedade. A favela, como retrata a autora, é o quarto de despejo da cidade grande.

\begin{abstract}
A resistência/agência que emerge de sujeitos historicamente invisibilizados, considerados subalternos ou não inteligíveis dentro de uma determinada ordem social, que podem estar relacionados tanto a certas identidades sociais, grupos, como, até mesmo, na relação entre nações "hegemônicas" e "emergentes".

São os processos de resistência a uma determinada hegemonia social, cultural, política que possibilita a mudança na cadeia de repetições das normas, dos modelos socialmente inteligíveis, seja em relação ao gênero, seja até mesmo em relação a outros marcadores sociais ou grupos minoritários (FURLIN, 2013, p. 401).
\end{abstract}

Assim, a trajetória de Carolina é exemplificadora de como se constitui a agência segundo o pensamento de Butler.

\title{
4. CONSIDERAÇÕES FINAIS
}

O diário de Carolina apresenta uma escrita que revela uma experiência individual e coletiva. É a memória de uma mulher marginalizada, como tantas outras que vivam na favela, mas também de crianças, homens, migrantes nordestinos, concepções vigentes.

É uma história que sai do cenário da invisibilidade a partir do olhar feminino, como afirma Bahia (2000, p. 70): “escrever como mulher é lançar-se num horizonte para além do que o movimento histórico lhe vinha permitindo". E deste modo, Carolina demonstra que a agência também nasce da subordinação. Pois, o sujeito não é predestinado a ser eternamente sujeitado e nem completamente livre (BUTLER, 1999).

A reflexão do pensamento de Butler a partir do Quarto de despejo possibilitou olhar para aqueles que são silenciados cotidianamente, e buscam um espaço para expor sua fala. Pois, a teoria da filósofa norte-americana e pós-estruturalista permite compreender como os grupos sociais excluídos constroem processos de resistência e de agência ressignificando suas práticas sociais.

\section{Notas de rodapé}

Educação, Psicologia e Interfaces, v. 2, n. 1, p. 152-166, Janeiro/Abril, 2018 


\begin{abstract}
${ }^{1}$ Em 1930, em razão das dificuldades econômicas, muda-se para Franca, passando o primeiro ano na fazenda Santa Cruz e, depois, na cidade, onde trabalhou como ajudante na Santa Casa de Franca, auxiliar de cozinha e doméstica. Com o falecimento da mãe em 1937, migra para São Paulo em busca de melhores condições de vida.

${ }^{2}$ Portanto, o jornalista não enfatiza a favela como algo exótico. Hoje temos um contexto diferente de apresentação das favelas: as experiências dos moradores são apresentadas como espetáculo para visitantes, em alguns momentos destacam-se as manifestações culturais, em outros, as estratégias de sobrevivência criadas pelos moradores. No Rio de Janeiro, por exemplo, temos carros que levam turistas para conhecer a realidade desses espaços.

${ }^{3}$ Temos nesse momento uma aproximação do pensamento de Butler com o conceito de habitus do sociólogo francês Pierre Bourdieu.

${ }^{4}$ Butler (2009b) utiliza a obra Antígona para exemplificar como o desejo opera.

${ }^{5}$ JESUS, Carolina Maria de. Diário de Bitita. Rio de Janeiro: Nova Fronteira, 1986.

${ }^{6}$ Quarto de Despejo: Diário de uma Favelada, publicado em 1960, teve um notável sucesso editorial. Carolina comprou uma casa no bairro de Santana, e mudou-se par lá. Depois foi editado Casa de Alvenaria: Diário de uma Ex-favelada, em 1961. Em 1963, publica Pedaços da Fome, seu único romance, que tem pouca repercussão.
\end{abstract}

\title{
REFERÊNCIAS BIBLIOGRÁFICAS
}

ANZALDUA, Gloria. Falando em línguas: uma carta para as mulheres escritoras do terceiro mundo. Rev. Estud. Fem. [online]. 2000, vol.08, n.01, pp. 229-236. Disponivel em: https://periodicos.ufsc.br/index.php/ref/article/view/9880/9106 Aceso em: jan. 2018.

BAHIA, Mariza Ferreira. O legado de uma linhagem: A literatura memorialística feminina. Tese de Doutorado em literatura comparada. Faculdade de letras de UERJ. Rio de Janeiro. Junho de 2000.

BAKHTIN, Mikhail. A estética da criação verbal. São Paulo: Martins Fontes, 1992.

BUTLER, Judith. Al lado de uno mismo: em lós limites de La autonomia sexual. In:

Deshacer el gênero. Barcelona: Paidós, 2006, p. 35-66.

Vida precária. In: Contemporânea n. 1, Jan-Jun. 2011, p. 13-33.

Cambio Del sujeto: La política dela resignificación radical de Judith Butler. In: CASALE, Roland; CHIACHIO, Cecília (Org.). Máscaras del deseo: uma lectua del deseo em Judith Butler. Buenos Aires: Catálagos, 2009b.

La vida psíquica del poder. Teorías de la sujeción. Feminaria. Ano X, n² 22/23. Buenos Aires, julio de 1999.

CAZAROTTO, J. L. Tempo e Escritura: uma terapêutica da narrativa. Disponível em: <http://www.cesjf.br/cesjf/index.php?centro=diretoria_geral1\&lado=lado_inst>. Acesso em: 2 de dez. 2014.

FEMENÍAS, María Luisa. Sobre o sujeto y gênero: lecturas feministas desde Beauvoir a Butler. Bueno Aires: Catálogos, 2000.

Educação, Psicologia e Interfaces, v. 2, n. 1, p. 152-166, Janeiro/Abril, 2018.

DOI: https://doi.org/10.37444/issn-2594-5343.v2i1.119 
GIL, Antônio Carlos. Como elaborar projetos de pesquisa. 4. ed. São Paulo: Atlas, 2008.

HOOKS, BELL. Intelectuais Negras. Estudos Feministas, Rio de Janeiro, v. 3, n. 2, p.464-478, 1995.

JESUS, Carolina Maria de. Quarto de despejo: diário de uma favelada. São Paulo: Francisco Alves, 1960.

LOPES, Eliane Marta Teixeira \& GALVÃO, Ana Maria de Oliveira. 2001. História da Educação. Rio de Janeiro: DP\&A. (O que você precisa saber sobre).

PERROT, Michelle. In: SMITH, Sidone. Hacia uma poética de la autobiografia de mujeres. In: Suplemento Anthropos: la autobiografia y sus problemas teóricos: estúdios e investigación documental nº 29, 1991, p. 97.

SÁ-SILVA, Jackson Ronie; ALMEIDA, Cristóvão Domingos, GUINDANI, Joel Felipe. Pesquisa documental: pistas teóricas e metodológicas. Rev. Brasileira de História \& Ciências Sociais. n. I, p. 1-15, jul., 2009

\section{Credenciais da autora}

CARDOSO, Elna Dias. Graduada em Ciências Sociais (UFPa), Mestre em Antropologia Social (UNB) e Doutoranda em Sociologia pela UFG. E-mail: elnaeenzo@gmail.com

Endereço para correspondência: Elna Dias Cardoso, Rua 121, nº 7, Bairro: Águas Claras, CEP: 71961-180 Cidade: Brasília- DF. E-mail: elnaeenzo@gmail.com

Como citar este artigo (Formato ABNT): CARDOSO, Elna Dias. Quarto de despejo: breve reflexão a partir dos conceitos de sujeito e agência de Judith Butler. Educação, Psicologia e Interfaces, v. 2, n.1, 152-166, 2018. DOI: https://doi.org/10.37444/issn2594-5343.v2i1.119

Recebido: 04/01/2018.

Aceito: 26/02/2018.

Educação, Psicologia e Interfaces, v. 2, n. 1, p. 152-166, Janeiro/Abril, 2018 